\title{
Erratum to: Effects of alkaline hydrolysis and autoclaving on inorganic components present in healthcare waste
}

\author{
S. C. Pinho ${ }^{1}$ M. F. Almeida ${ }^{1}$ O. C. Nunes ${ }^{2}$
}

Published online: 14 December 2015

(C) Islamic Azad University (IAU) 2015

Erratum to: Int. J. Environ. Sci. Technol. (2015)

$$
\begin{aligned}
& \text { 12:1191-1200 } \\
& \text { DOI 10.1007/s13762-014-0503-5 }
\end{aligned}
$$

The Acknowledgments in the original version are incomplete. Please find the complete Acknowledgments here.

Acknowledgments S. C. Pinho thanks the Fundação para a Ciência e Tecnologia for the fellowship SFRD/BD/48956/2008 and Anthony Danko for his corrections to the manuscript. This work was supported by Funds FEDER through the Operational Programme Competitiveness Factors-COMPETE and National Funds through FCT-Fundação para a Ciência e a Tecnologia under the project PTDC/SAUSAP/114855/2009, FCOMP-01-0124-FEDER-016017.

The online version of the original article can be found under doi:10.1007/s13762-014-0503-5.

S. C. Pinho

scpinho@fe.up.pt

1 LEPABE, Department of Metallurgical and Materials Engineering, Faculty of Engineering, University of Porto, Rua Dr. Roberto Frias, 4200-465 Porto, Portugal

2 LEPABE, Department of Chemical Engineering, Faculty of Engineering, University of Porto, Rua Dr. Roberto Frias, 4200-465 Porto, Portugal 